\title{
Substantiation of work quality indicators of the universal seeds scarificator of the eastern galega (Galega Orientalis)
}

\author{
Eduard Khasanov, Salavat Mudarisov, Rim Khamaletdinov, Airat Mukhametdinov, \\ Damir Maskulov, Radik Musin \\ Department of Road Construction, Communal and Agricultural Machines, Federal State Budgetary Educational \\ Establishment of Higher Education 'Bashkir State Agrarian University', Ufa, Russian Federation
}

\begin{abstract}
Eastern galega (Galega orientalis) contains amino acids and vitamins necessary for the normal functioning of the animal organism. In addition, it is a good precursor to many cultures. One of the drawbacks of Eastern galega is the hard shell of the seeds, which leads to increased seed consumption, a prolonged time of seedlings and an irrevocable loss of part of the sown seeds. The most affordable, simple and productive is the mechanical method of violating the tightness of the coating film of seeds. The aim of the study was to conduct comparative experiments with the existing scarifier, to create an improved design of a disk scarifier, which allows to improve the quality of seed treatment, and the theoretical justification of its structural and technological parameters. The original design of the disk scarifier on the seeds of the Eastern galega was investigated. The working bodies of the blades of the scarifier disc and their changing installation angle allows to adjust the contact angle of the seeds with the abrasive surface of the grinding wheel, thereby scratching the hard shell of the seeds without injuring them. In contrast to the used designs of scarifiers, the device under development provides for a pneumatic system for removing dust and impurities from the abrasive surface of the grinding wheel by the air flow and additional seed treatment with the microbiological preparation rhisotorfin. In the study of qualitative indicators of scarification of Eastern galega at an average moisture content of $9 \%$, the following parameters were deter-
\end{abstract}

Correspondence: Eduard Khasanov, Department of Road Construction, Communal and Agricultural Machines, Federal State Budgetary Educational Establishment of Higher Education 'Bashkir State Agrarian University', Ufa, 50-letia Octyabrya str., 34, 450001, Russian Federation.

E-mail: eduard.khasanov.82@mail.ru

Key words: Scarification; seed scarifier; germination; rotating disk; degree of scarification; degree of crushing.

Received for publication: 5 December 2019.

Accepted for publication: 8 July 2020.

${ }^{\circ}$ Copyright: the Author(s), 2020

Licensee PAGEPress, Italy

Journal of Agricultural Engineering 2020; LI:1034

doi:10.4081/jae.2020.1034

This article is distributed under the terms of the Creative Commons Attribution Noncommercial License (by-nc 4.0) which permits any noncommercial use, distribution, and reproduction in any medium, provided the original author(s) and source are credited. mined: seed germination, $\%$; the degree of scarification, $\%$ and the degree of crushing of seeds, $\%$ with disk rotation modes - 700, 900 , $1100,1300,1500 \mathrm{rpm}$. The studies have shown high-quality seed treatment compared to its counterpart. In the recommended range of disk revolutions of $900 \ldots 1100$, the proposed scarifier showed a decrease in the degree of crushing of seeds by $0.2 \ldots 0.4 \%$, an increase in the degree of scarification by $2 \ldots 3 \%$ and the degree of germination by $4 \ldots 5 \%$. The use of the developed design of the scarifier in international practice will reduce the damage of the treated seeds and increase the yield of legumes.

\section{Introduction}

An important role in the production of legumes is played by seed material, the quality of which, along with other parameters, is determined by germination, which is adversely affected by the hard, tight shell of the seeds impermeable to water and air, inhibiting the swelling of seeds, not allowing the embryo to develop (Rehal et al., 2019). These, leading to the delay in the germination of seedlings, loss of part of the sown seeds, and reduced yield (Rusdy, 2017). The solution to this issue is a violation of the integrity of the seed coat in various ways. This technique of preparing seeds for sowing is called scarification, and the technical devices used for this process are called scarifiers (Galíndez et al., 2016).

In addition to grass seeds and forage crops, various methods of scarification are effective for farm crops - wheat, oats, barley, peas, onions, carrots, spinach, radishes, beets, parsley, cabbage, tomato, cilantro, dill (Janushko, 2010), as well as for seeds of forest crops (Cochrane, 2017; Jabłoński et al., 2018). But scarification is especially widely used for legumes (Zhetkergenkyzy et al., 2015).

The practical methods for seed scarification before sowing include: mechanical (physical impact); chemical (acid treatment); thermal (warming and freezing); ultrasound (processing in an ultrasound field). The first three methods are most widespread; processing in an ultrasonic field at the given time is not widely used (Zubova, 2017). There are various points of view on the effectiveness and advantages of a particular method of scarification.

The randomised studies conducted in Brazil with wood bean on its scarification with sandpaper (mechanical scarification), immersion in concentrated $\mathrm{H}_{2} \mathrm{SO}_{4}$ (chemical) and hot water (thermal) in the time interval of $5 \div 20 \mathrm{~min}$ with intervals of $5 \mathrm{~min}$ showed that the most effective treatment was chemical (20 min treatment with germination of $93.0 \%$ of viable seeds), the lowest efficiency was shown by heat treatment (Bichoff et al., 2018). The same conclusions were reached by Czech researchers during the scarification of the mucuna-preta bean culture (de Oliveira et al., 
2017). The scientists who have carried out the scarification for five local legumes in the Arabian desert in Qatar also note that chemical scarification is more preferable (Bhatt et al., 2016).

In turn, the experiments with four types of legumes in Argentina showed that heat treatment is most effective for the species T. subterraneum (Mira et al., 2017). The same conclusions were reached by Canadian scientists who studied the effect of scarification on the germination of three species of clover (Schellenberg and Biligetu, 2015). At the same time, scientists from different countries obtained data indicating the advantages of mechanical treatment (Mirsky et al., 2015; Nagar and Meena, 2015; Statwick, 2016; Müller et al., 2017). In our opinion, and this is confirmed by research (Koobonye et al., 2018), chemical and thermal scarification of seeds, with all its advantages, is rarely used in mass production. With mechanical scarification, in the case of mass processing of large batches of seeds, with the use of technical devices - scarifiers, significantly reducing the complexity of the process, it is possible to achieve the required quality of processing with a high level of seed germination (Koobonye et al., 2018).

The researchers Luo et al. (2013) created and tested the design of the 9BQS-3.0 machine with a pneumatic scarification and sowing complex, which proved to be quite good in simultaneous operations of seed scarification and sowing in China. The researchers Bouteiller et al. (2017) conducted research on the use of an automatic grinding machine for forest seeds and recommended shortterm grinding ( $5 \mathrm{~min}$ ) to achieve the best results. In the USA, a mechanical electric drum scarifier coated with 80 grit sandpaper was used to scarify Waltheria indica seeds, ensuring seed germination after treatment for 15 or $30 \mathrm{~s}$ by $95 \%$ and $99 \%$, respectively (Lukas et al., 2016).

Mechanical scarification in agriculture and forestry is also widely used in Russia, the existing scarifiers are being modernised and new ones are being designed (Zubova, 2017), parameters are being introduced to evaluate the quality indicators of the scarifier (Shevchenko et al., 2018).

We conducted experimental studies of leguminous seed scarifiers available in the Republic of Bashkortostan, determining that the existing designs are imperfect and have a number of drawbacks, which is also confirmed by other researchers: insufficiently high quality of scarification (Verbovskij, 2009); repeated impacts on some of the seeds on the scarifying surface and, accordingly, their increased damage (Lukin, 2013). In addition, the production often faces the task of treating scarified leguminous seeds with the microbiological preparation rhizotorfin, which is done manually.

\section{Materials and methods}

\section{Experimental studies with an existing scarifier model}

Experimental studies were conducted to determine the quality of scarification with the existing model of the SK-300 scarifier (Pensmash, http://penzmash.ru/root/) to identify shortcomings and further ways to eliminate them. The determination of quality indicators was carried out according to the method proposed by Burkov et al. (2014) below. It was revealed that, along with the above disadvantages, the technological process using the scarifier used in the production consists of several separate operations: seed scarification; manual cleaning of seeds from dust and impurities formed during scarification; manual processing of peeled seeds on a tarpaulin biological product. This implies the need to improve the structural and technological parameters of the scarifier in order to eliminate the identified shortcomings.

\section{The design of the scarifier and the principle of its oper- ation}

For research, a disk scarifier design is proposed (Figure 1), the technological process of which is as follows. Eastern galega (Galega orientalis) seeds are loaded into the hopper and the drive is turned on. The metering device sets the seed supply on a rotating disk with blades, on which the seeds move along a path close to the logarithmic spiral until they meet with the blade (scarification zone I). The blades change the direction of movement of the seeds, while increasing their speed. Descending from the disk, the seeds come into contact with the abrasive surface of the grinding wheel, thereby undergoing scarification by scratching the hard shell and creating the possibility of penetration of moisture and air to the seeds. The shape of the blades and their changing installation angle allows adjusting the angle of contact of the seeds with the abrasive surface. After contact, the dust and impurities formed from the abrasive surface of the grinding wheel are captured by the air flow (cleaning zone II) formed by the fan, and through the air ducts they leave the unit. Scarified seeds fall onto the cone guide and roll onto the lower disc.

Next, the seeds are treated with rhizotorfin (seed treatment area with preparation III). The microbiological preparation from the tank through the pipeline and a sprayer in the form of aerosol droplets formed covers the scarified seeds as they roll down from the cone guide to the lower disk. In addition, on a rotating lower disk, the seeds are additionally treated with aerosol drops, providing quality processing. Spray pressure is provided by a pump with a regulator. After that, the processed seeds are delivered to the container.

In the study of qualitative indicators of scarification of Eastern galega seeds at an average moisture content of $9 \%$, the following parameters were determined: seed germination, $\%$; the degree of scarification, $\%$ and the degree of crushing of seeds, $\%$ under disk rotation modes - 700, 900, 1100, 1300, $1500 \mathrm{rpm}$ (Figure 1).

\section{The mathematical model of the pneumatic system for removing dust and impurities}

For a theoretical description of the technological process of formation, movement and removal of dust particles and impurities in a seed stream by a pneumatic system (zone II of Figure 1), we propose using methods of mechanics of two-phase gas-particle flows (Mudarisov et al., 2017). Usually, for the mathematical description of the gas flow with particles, the Navier-Stokes system of equations is used with the addition of continuity equations to this system, mass conservation for the formed mixture, and momentum conservation. However, for the mathematical description of the operation of the pneumatic system of the scarifier, it is necessary to establish the possibility of applying the methods of two-phase flows as applied to its technological process. For this, it is necessary to establish the flow regime of the gas-particle mixture (air-dust and air-seeds), determined by the Reynolds number $\mathrm{Re}_{\mathrm{p}}$ and the volume concentration of particles $\alpha_{c}$. To determine these parameters, in turn, you need to know the amount of transported material and the speed of air flow and particles, as well as their drag coefficient.

Having determined these indicators by the method (Mudarisov et al., 2017), we obtained the parameters of the air-grain mixture in the pneumatic system of the scarifier:

- the speed of the air flow to ensure the transportation of seeds 
of various crops $\mathrm{vg}_{\mathrm{g}}=17 \div 24 \mathrm{~m} / \mathrm{s}$;

- the speed of the air flow to ensure the transport of droplets $\mathrm{Vg}$ $=45 \div 75 \mathrm{~m} / \mathrm{s}$;

- volumetric concentration of seeds $\alpha_{c}=0.0003 \div 0.0015$;

- volumetric concentration of drops $1.14 * 10^{-7}<\alpha_{\kappa}<3.8^{*} 10^{-7}$;

- Reynolds number of drops $\mathrm{Re}_{\mathrm{p}}=61 \div 205$;

- Reynolds number of seeds $\mathrm{Re}_{\mathrm{p}}=980 \div 4800$;

- $\quad$ Seed resistance coefficient $C_{D}=0.35 \div 0.50$.

The low volume concentration of seeds and drops makes it possible to use the methods of mechanics of two-phase media for the mathematical description of the operation of pneumatic scarifier systems. The Reynolds number of solid (seeds) and liquid (droplets) particles allows us to determine their drag coefficient in the equations of particle dynamics for any point in the considered region of the pneumatic system. The calculated values of the air flow speed allow choosing a fan and justifying the frequency of rotation of its blades to ensure the transportation and distribution of particles.

To substantiate the constructive and technological parameters of the seed scarifier by laboratory tests, it was found that in cases where $60 \div 80 \%$ of dust particles and impurities have a diameter of up to $2 \mu \mathrm{m}, 10 \div 20 \%$ - from 2 to $5 \mu \mathrm{m}$ and up to $10 \%$ - over $10 \mu \mathrm{m}$ and at the same time, the speed of their soaring at the level of $0.000018-0.58 \mathrm{~m} / \mathrm{s}$, the air flow created by the fans sucks them in with an average speed of about $0.26-0.54 \mathrm{~m} / \mathrm{s}$ from the lower and middle parts of the processing chamber to the intake parts of the fan ducts. So, the recommended air flow rate should be $0.8-2.5$ $\mathrm{m} / \mathrm{s}$, in order to ensure that the scarified seeds are cleaned of dust and impurities formed during processing on the one hand and, on the other hand, that goat seeds are not sucked into air ducts of size 2, 5-3 $\mathrm{mm}$ (soaring speed 7-9 m/s) and droplets of rhizotorfin 300400 microns in size (soaring speed 2.7-7.4 m/s).

These factors are favourable and necessary to ensure the tech-

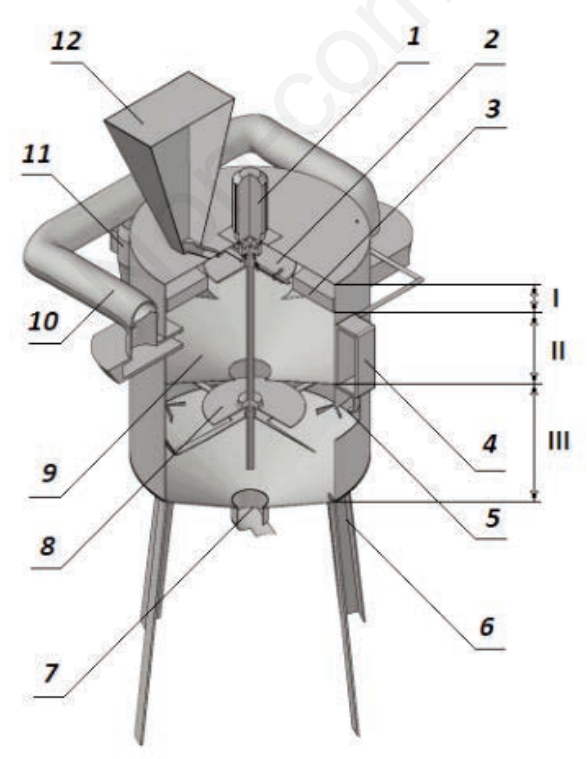

$\mathbf{A}$

Figure 1. Experimental seed scarifier: A) 3D drawing; B) appearance: 1- electric motor; 2- upper blade disc; 3- abrasive surface of the grinding wheel; 4- adjusting crane; 16-tank with a microbiological preparation rhizotorfin; 5- sprayer; 6- pillar; 7- way window with shutter; 8- lower disk; 9- conical guide; 10- air duct; 11- fan; 12- hopper for seeds; I - scarification zone; II - zone for cleaning seeds from dust and impurities; III - seed treatment zone. nological process of scarification with the required quality of processing. To confirm the calculated and experimental data, modelling was carried out in the developed mathematical model for the flow of a two-phase air-particle medium and its numerical implementation in the FlowVision software package.

Since modern methods of numerical simulation have not yet reached the possibility of modelling the complete technological process of seed treatment inside a technical device, we have developed a model for the interaction of the air flow with the Polisorb VP powder preparation, which in its dimensional characteristics corresponds to dust and impurities remaining after seed scarification. The speed of their soaring in this case is in the range of $0.000018-0.58 \mathrm{~m} / \mathrm{s}$ (Yanchenko, 2000).

Using the FlowVision software package made it possible to visualise the movement of the air flow in the zone for cleaning seeds from dust and impurities (zone II of Figure 1), as well as to obtain the results of calculations of the velocity, pressure and trajectories of particles (dust and impurities) at any point.

The analysis of Figure 2 shows that the air flow is directed from the bottom and centre of the processing chamber to the fan ducts.

The maximum air flow rate was noted at the junction of the treatment chamber and fans and is approximately $9 \mathrm{~m} / \mathrm{s}$. In the central zone of the treatment chamber, the speed is low and amounts to $0.08-0.79 \mathrm{~m} / \mathrm{s}$.

Figure 3 shows that dust particles and impurities with an average speed of about $6 \mathrm{~m} / \mathrm{s}$ move along the fan duct, that is, they are sucked off and removed from the treatment zone, and therefore favourable working conditions are created during seed treatment with the drug. At the same time, Eastern galega seeds of 2.5-3 mm in size with a soaring speed of $7-9 \mathrm{~m} / \mathrm{s}$ and droplets of a treating liquid of 300-400 microns in size with a soaring speed of 2.7-7.4 $\mathrm{m} / \mathrm{s}$ cannot be carried away by the air flow.

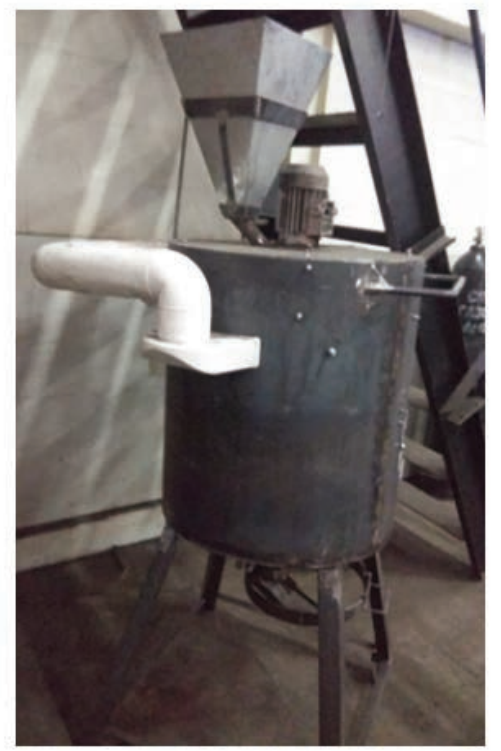

B 
Thus, the developed mathematical model of the two-phase airparticle flow and its numerical implementation in the FlowVision software package confirms the operability of our proposed flow chart of a scarifier with the additional function of cleaning seeds from dust and impurities before processing with a microbiological preparation.

\section{The statistical data processing}

The methodology for determining indicators is based on a method for determining the quality indicators of the work of scarifiers, proposed by Burkov et al. (2014). Before each experiment, in accordance with State Standard 12036-85 (2011), two weighed samples of eastern Galega seed seeds of $500 \mathrm{~g}$ each were taken from the starting material fraction. Four samples of 100 seeds each were taken from the first sample (control) and from the second one, which were passed through a scarifier, to determine seed germination. In addition, an average sample of $20 \mathrm{~g}$ was taken from the second sample and determined by analysis (State Standard

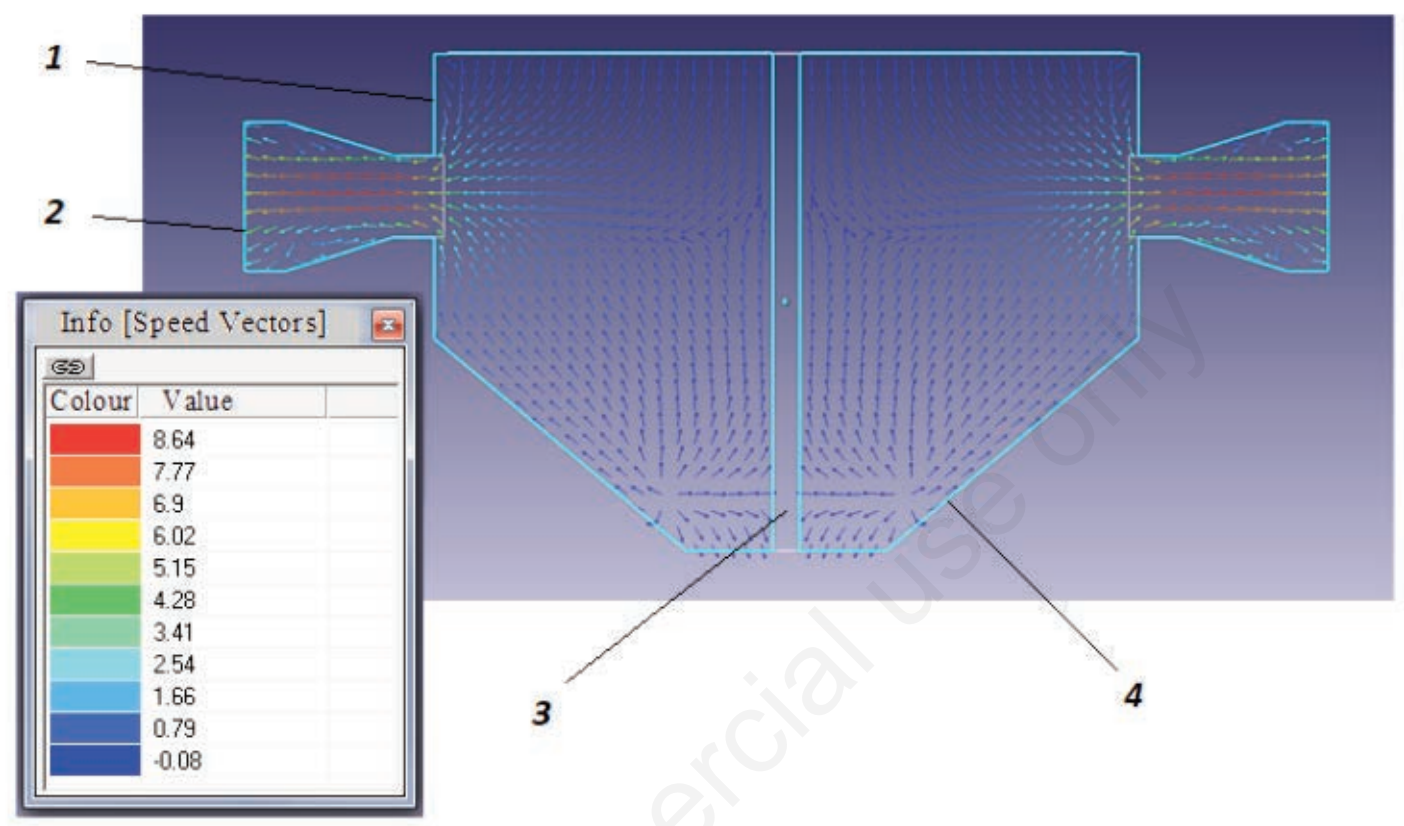

Figure 2. Fragment of the motion of air velocity vectors visualisation in the ZY plane in the FlowVision software package (II zone for cleaning seeds from dust and impurities): 1- housing wall; 2- part of the duct; 3-drive shaft; 4- cone guide.

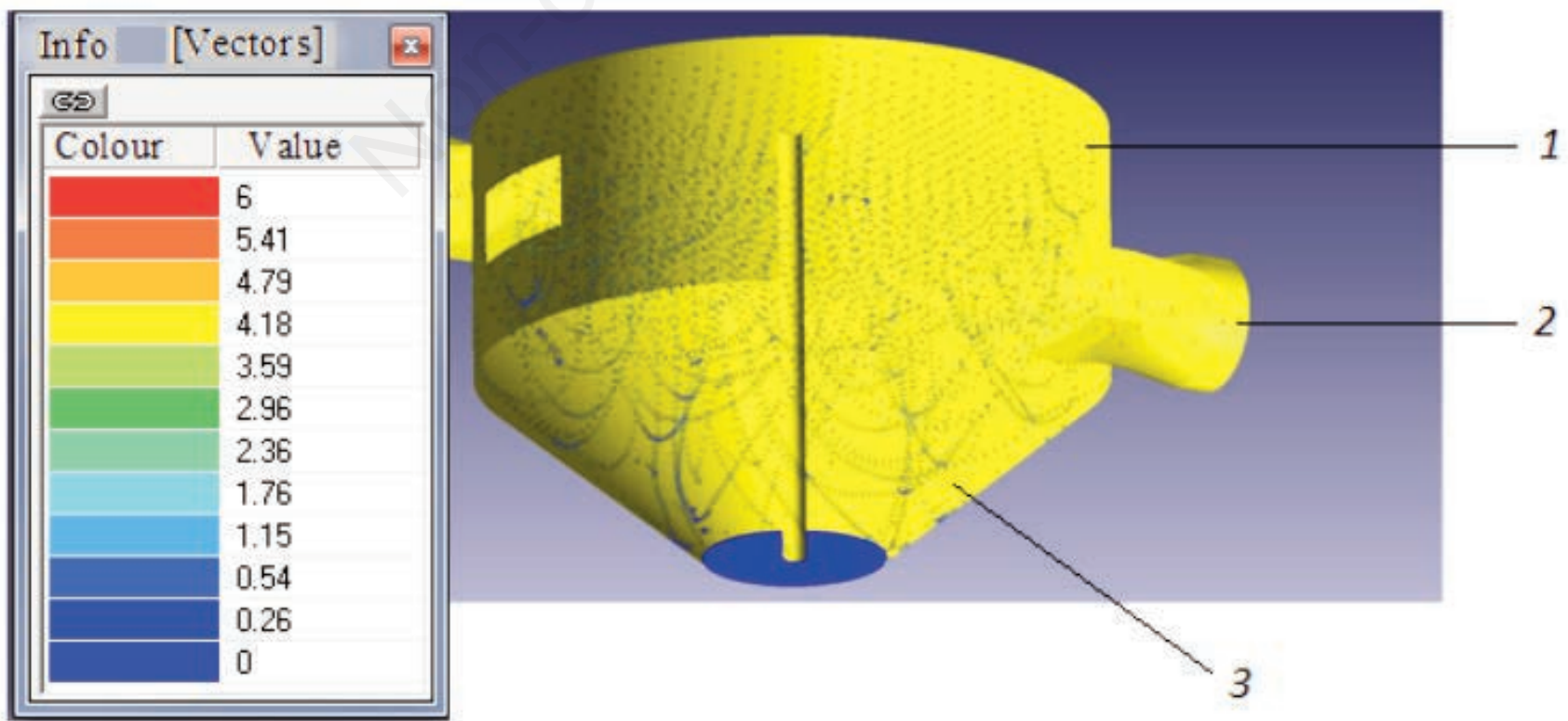

Figure 3. Fragment of visualising the movement of particles in air flows in the ZY plane in the FlowVision software package (II zone for cleaning seeds from dust and impurities): 1- housing wall; 2-part of the duct; 3-cone guide. 
12037-81, 2011) the amount of crushed seeds in it. After recounting the total mass of scarified seeds, a mass of crushed seeds was obtained. The degree of crushing of seeds was determined by the expression, $\%$

$$
d=\frac{m_{d \mathrm{c}}}{m_{\mathrm{H} 2}} 100
$$

where $m_{d c}$ is the mass of crushed seeds in the second sample, $\mathrm{kg}$; $\mathrm{m}_{\mathrm{H} 2}$ is the mass of the second sample, $\mathrm{kg}$.

To determine the germination rate, the method of seed germination between paper was used - samples characterising the sowing quality of seeds before and after processing, respectively. For this, at the end of 14 days, the number of seeds sprouted and hard (which did not swell and did not change the appearance) was calculated by the established date for determining germination.

The germination was determined as, $\%$ :

$$
B=\frac{(S+K)}{R} 100
$$

where $\mathrm{S}$ is the total number of seeds germinated after 14 days; $\mathrm{K}$ is the amount of hard seeds, $R$ is the amount of hard seeds, is laid in the sample.

The arithmetic mean value of all analysed samples was taken as the result of the analysis. If the deviation of the parameter values in one of the analysed samples from the arithmetic mean value is greater by a value, then the germination rate was determined by the analysis of the remaining three samples. If such a deviation has another sample, then the analysis was repeated.

The degree of scarification was determined as the ratio of the dif- ference in the number of hard seeds in samples before and after treatment to the amount of hard seeds in samples before treatment, $\%$ :

$$
C=\frac{K_{1}-K_{2}}{K_{1}} 100
$$

where $K_{1}$ is the amount of hard seeds in the sample before processing; $K_{2}$ - the amount of hard seeds in the sample after processing.

\section{Results and discussion}

To compare the experimental data, the comparative studies of our proposed scarifier with the CK-300 (PJSC 'Penzmash'), were carried out.

Figure 4 shows the obtained data on the germination and degree of scarification of Eastern galega seeds after processing on the proposed scarifier and the existing CK-300 scarifier. The analysis of the germination data indicates that the quality indicators of the proposed scarifier are higher than those of the existing one, the same is observed in terms of the degree of scarification. The recommended modes in this case are the range of $900 \div 1100$ revolutions of the disk, in which the degree of seed germination is $90 \div 91 \%$ without treatment with rhizotorfin, and the degree of scarification is $87 \div 92 \%$. The data on the degree of scarification of seeds presented in Figure 1 suggest that with an increase in the number of revolutions and, accordingly, the speed of impact of seeds on the abrasive surface (the degree of roughness of the abrasive wheel is $40 \mu \mathrm{m})$, the degree of scarification increases from $84 \%$ at $700 \mathrm{rpm}$ to $98 \%$ at $1500 \mathrm{rpm}$.

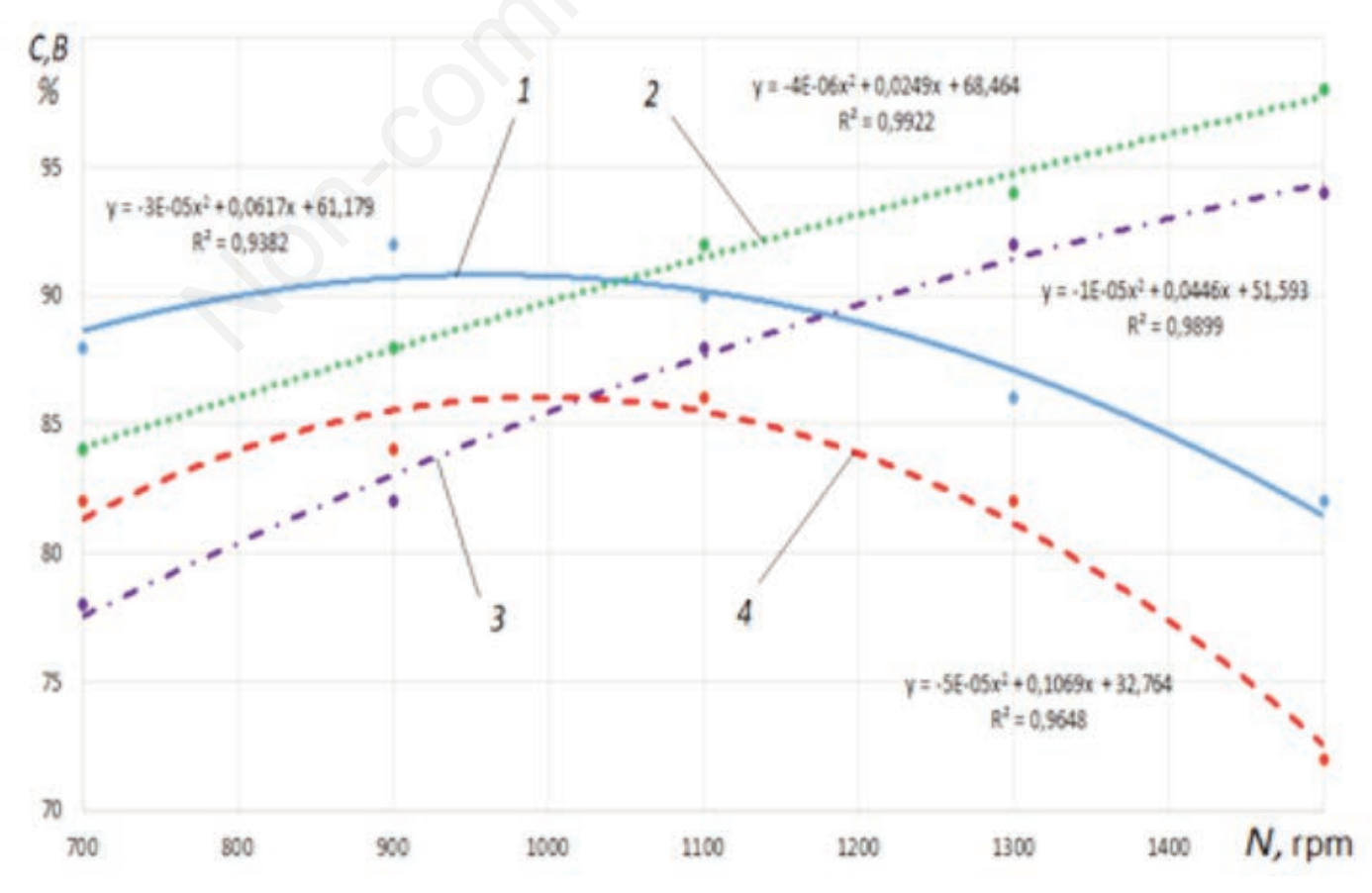

Figure 4. Dependences of the quality indicators of the proposed and existing scarifiers on the number of disk revolutions: (degree of germination: 1 - of the proposed scarifier, 4 - of the CK-300 scarifier; degree of scarification: 2 - of the proposed scarifier, 3 - of the CK-300 scarifier). 
But along with this, the degree of crushing of seeds also increases, which is an unfavourable factor during processing (Figure 5). With the recommended regime of the disc rotation range of $900 \div 1100$, the degree of crushing of seeds will be $1.2 \div 2.0 \%$, which is permissible by agrotechnical standards.

The experimental data on the quality of work of the proposed seed scarifier showed that mechanical scarification is preferable when processing large quantities of legume seeds in production, significantly reducing the complexity of the process. This is also evidenced by the results of other researchers (Nagar and Meena, 2015; Bouteiller et al., 2017; Müller et al., 2017; Koobonye et al., 2018).

Unlike other used disk scarifiers, we propose, in addition to mechanical scarification, to carry out additional processing of scarified Eastern galega with the microbiological preparation rhizotorfin in the device, having previously cleaned the seeds of dust and impurities by air flow.

The parameters of the pneumatic seed cleaning system are determined by simulation. The experimental data were confirmed by theoretical studies of the mathematical description and modelling in the form of a polydisperse two-phase flow taking into account the concentration, air flow velocity, and drag coefficient. Similar studies were carried out by other scientists, which are reflected in the works (Kutzbach and Quick, 1999; Miu, 2015).

A comparative analysis of theoretical and experimental studies has shown that reliability is greater than 0.95 according to Student's $t$-criterion, which suggests that it is possible to accept the results as reliable.

The obtained characteristics allow us to develop recommendations for optimising the structural and technological parameters of the pneumatic system and the design of the developed scarifier as a whole.

The proposed design of a universal seed scarifier will reduce the damage to the treated seeds and increase the yield of legumes.

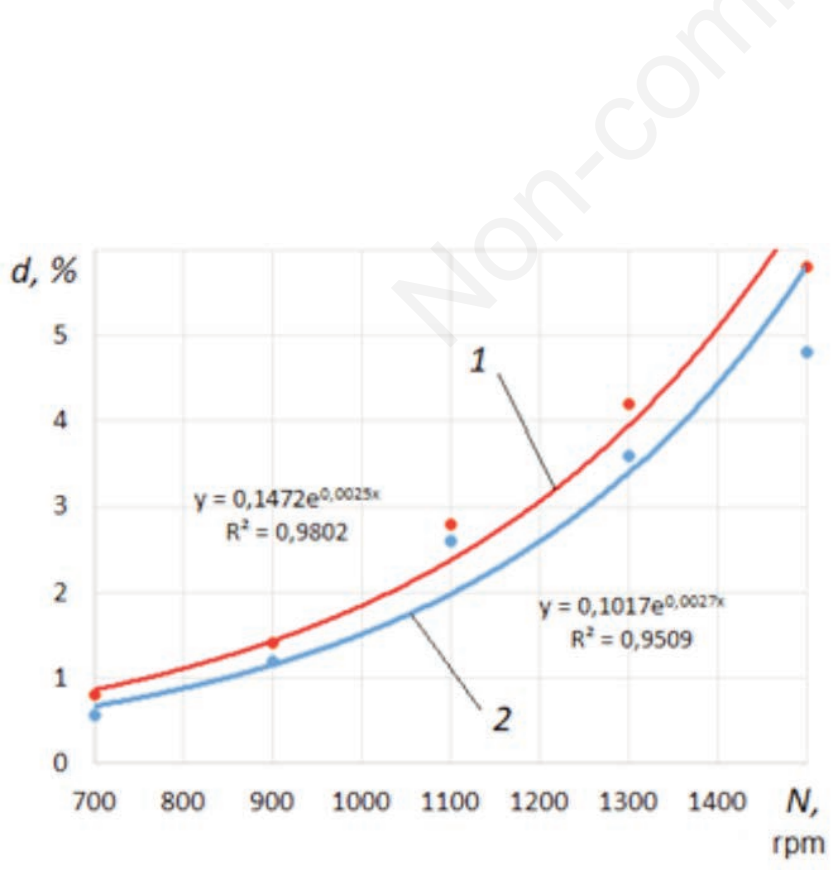

Figure 5. Dependence of the degree of crushing of the proposed and existing scarifiers on the number of revolutions of the disk (1 - scarifier CK-300; 2 - proposed scarifier).

\section{Conclusions}

In the proposed scarifier, two operations are sequentially performed - scarification and treatment with a microbiological preparation. The use of the developed device for scarification of Eastern galega seeds ensured high-quality pre-sowing treatment of seeds. Compared with the existing scarifier, in the recommended range of disc speeds of $900 \div 1100$, the proposed scarifier showed a decrease in the degree of crushing of seeds by $0.2 \div 0.4 \%$, an increase in the degree of scarification by $2 \div 3 \%$ and the degree of germination by $4 \div 5 \%$.

In contrast to the disk scarifiers used in Russia and abroad, we propose, in addition to mechanical scarification, to carry out additional processing of scarified goat seeds with the microbiological preparation rhizotorfin in the device, having previously cleaned the seeds of dust and impurities by air flow. The pneumatic cleaning system proposed in this case is calculated in a mathematical model of the technological process of work by the methods of mechanics of two-phase flows. The obtained parameters allow us to establish that to simulate the technological process of the dust and premix cleaning system, two-phase gas-particle flow methods can be used.

\section{References}

Bhatt A., Carón M.M., Verheyen K., Elsarrag E., Alhorr Y. 2016. Germination and seedling performance of five native legumes of the Arabian Desert. Flora: Morphology, Distribution, Funct. Ecol. Plants 220:125-33.

Bichoff R.S., Okumura R.S., Oliveira R.S., Sodre D.C., Valente G.F. 2018. Overcoming seed dormancy and evaluation of viability in Leucaena leucocephala. Aust. J. Crop Sci. 12:168-72.

Bouteiller X.P., Porté A.J., Mariette S., Monty A. 2017. Using automated sanding to homogeneously break seed dormancy in black locust (Robinia pseudoacacia L., Fabaceae). Seed Sci. Res. 27:243-50.

Burkov A.I., Simonov M.V., Mokiev V.J. 2014. The method of determining the performance indicators of scarifiers. Patent for invention $2564874 \mathrm{RF}, \mathrm{A} 01 \mathrm{C} 1 / 00$.

Cochrane A. 2017. Are we underestimating the impact of rising summer temperatures on dormancy loss in hard-seeded species? Aust. J. Bot. 65:248-56.

de Oliveira J.D., da Silva J.B., Alves C.Z. 2017. Treatments to increase, accelerate and synchronize emergence in seedlings of mucuna-preta. Rev. Cienc. Agron. 48:531-9.

Galíndez G., Ceccato D.V., Malagrina G.M., Pidal B., Chilo G.N., Bach H.G., Fortunato R.H., Ortega-Baes P. 2016. Physical seed dormancy in native legume species of Argentina. B. Soc. Argent. Bot. 51:73-8.

Jabłoński M., Tadeusiewicz R., Piłat A., Walczyk J., Tylek P., Szczepaniak J., Adamczyk F., Szaroleta M., Juliszewski T., Kiełbasa P. 2018. Vision-based assessment of viability of acorns using sections of their cotyledons during automated scarification procedure. Bio-Algorith. Med-Syst. 14: 20180006.

Janushko S.V., 2010. Methods of increasing the sowing qualities of legume seeds. Land Reclamat. 1:187-9.

Koobonye M., Maule B.V., Mogotsi K. 2018. Mechanical scarification and hot water treatments enhance germination of leucaena Leucocephala (Lam.) seeds. Livest. Res. Rural. Dev. 30:1-7.

Kutzbach H.D., Quick G.R. 1999. Harvesters and Threshers. 
Grain. pp 311-47 in CIGR Handbook of Agricultural Engineering, Volume III - Plant Production Engineering. ASAE, St. Joseph, MI, USA.

Lukas SB, DeFrank J, Baldos OC, 2016. Optimisation of Waltheria indica seed dormancy relief treatments and seed storage parameters. HortSci. 51:1184-7.

Lukin A.N. 2013. Parameters of a pneumatic scarifier for presowing seed treatment of perennial legumes: the dissertation for the degree of candidate of technical sciences. State Scientific Institution "Siberian Research Institute of Mechanisation and Electrification of Agriculture" of the Siberian Branch of the Russian Academy of Agricultural Sciences, Novosibirsk, Russian Federation.

Luo J., Sun J., Yang L., Wang Z., Li W., Dong Z. 2013. Design and experiment of type 9BQS-3.0 pneumatic scarifying and sowing compound operation machine. Nongye Jixie Xuebao/Trans. Chinese Soc. Agric. Machine. 44:51-66.

Mira S., Schnadelbach A., Correa E.C., Pérez-García F., GonzálezBenito M.E. 2017. Variability of physical dormancy in relation to seed mechanical properties of three legume species. Seed Sci. Technol. 45:540-56.

Mirsky S.B., Wallace J.M., Curran W.S., Crockett B.C. 2015. Hairy vetch seedbank persistence and implications for cover crop managemen. Agronomy J. 107:2391-400.

Miu P. 2015. Combine Harvesters: Theory, Modeling, and Design. CRC Press, Boca Raton, FL, USA, pp 494.

Mudarisov S., Khasanov E., Rakhimov Z., Gabitov I., Badretdinov I., Farchutdinov I., Gallyamov F., Davletshin M., Aipov R., Jarullin R. 2017. Specifying two-phase flow in modeling pneumatic systems performance of farm machines. J. Mech. Eng. Res. Develop. 40:706-15.

Müller F.L., Raitt L.M., Cupido C.F., Chimphango S.B.M., Samuels M.I., Boatwright J.S. 2017. Dormancy-breaking treatments in two potential forage crop legumes from the semi-arid rangelands of South Africa. S. Afr. J. Bot. 113:133-6.

Nagar R.P., Meena S.S. 2015. Effect of physical and chemical scarification and ageing on hardseededness in Clitoria ternatea. Range Manag. Agrofor. 36:79-83.
Rehal J., Beniwal V., Gill B.S. 2019. Physico-chemical, engineering and functional properties of two soybean cultivars. Legume Res. 42:39-44.

Rusdy M. 2017. A review on hardseedness and breaking dormancy in tropical forage legumes. Livest. Res. Rural. Dev. 29:237.

Schellenberg M.P., Biligetu B. 2015. The effects of temperature and scarification on seed germination of three dalea specie. Can. J. Plant Sci. 95:1117-20.

Shevchenko A.P., Bankrutenko A.V., Koval V.S., Begunov M.A., Demchuk E.V. 2018. Scarification of Seeds as an Increasing Element of Perennial Legume Grasses Productivity. J. Phys. Conf. Ser. 1059:012011.

State Standard 12036-85, 2011. Seeds of crops. Acceptance rules and sampling methods. Introduced. MState Standard of Russia: Publishing House of Standards, pp 13.

Statwick J.M. 2016. Germination pretreatments to break hard-seed dormancy in Astragalus cicer L. (Fabaceae). PeerJ 11:e2621.

Verbovskij A.V. 2009. Substantiation of parameters and operating modes of a disk scarifier for pre-sowing seed treatment of perennial legumes: the dissertation for the degree of candidate of technical sciences. State Scientific Institution "Siberian Research Institute of Mechanisation and Electrification of Agriculture" of the Siberian Branch of the Russian Academy of Agricultural Sciences, Novosibirsk, Russian Federation.

Zhetkergenkyzy M.G., Auelbekovich O.S., Serikkanuly M.N., Maikanovna S.B. 2015. Yield, fodder value and biologization of soil fertility increase with legume crops in the south-east of Kazakhstan. Bioscie. Biotech. Res. Asia 12:1223-31.

Zubova R.A. 2017. Substantiation of presowing treatment of seeds with hard shell ultrasound and ultra-high frequency electromagnetic field: the dissertation for the degree of candidate of technical sciences. Krasnoyarsk State Agrarian University, Krasnoyarsk, Russian Federation.

Yanchenko G.Y. 2000. To the calculation of the speed of the movement of dust particles in a dust and gas cloud. Mountain Inf. Analyt. Bull. 10:96-8. 